\title{
A ÉTICA COMO METAFÍSICA DA ALTERIDADE E SUAS POSSÍVEIS CONTRIBUIÇÕES AOS FUNDAMENTOS DA EDUCAÇÃO
}

\author{
Thaís de Oliveira Nabaes* \\ Vilmar Alves Pereira**
}

\begin{abstract}
RESUMO: Este estudo trata de uma aproximação entre Metafísica e Ética a partir da perspectiva de Emmanuel Levinas. Em um primeiro momento, revisita o sentido ontológico que o ser humano assume no contexto da racionalidade ocidental; a seguir, discute os limites para a efetivação de uma ética no bojo da racionalidade instrumental capitalista. Estudar o Ser não redunda necessariamente em entendimento ou acolhida daquilo que ele manifesta, ainda mais se os seres a que nos referimos são humanos. Se a chamada condição pós-moderna tem mostrado formas de ser-no-mundo esvaziadas de sentido e fundamentadas especialmente na possibilidade de consumir, Levinas procurou aprofundar o entendimento do humano sob o paradigma da Alteridade. Outros autores referenciados no texto concordam com a ideia de que a cosmovisão antropocêntrica do mundo moderno se tornou a raiz ideológica do capitalismo e de alguns de seus indesejáveis desdobramentos, como guerras, mazelas sociais e diversas formas de indiferença. Em contrapartida, ao repensar o primado da racionalidade ocidental, poderemos chegar a desenvolver uma subjetividade acolhedora. Destarte, partindo da perspectiva de Levinas, este texto pretende argumentar a favor de uma ética que, além de nos humanizar, se constitua em uma Metafísica da Alteridade. Este olhar ontológico redimensionado pode possibilitar novas compreensões ao campo dos Fundamentos da Educação, bem como propõe a necessidade de construção de novos modelos societários.
\end{abstract}

Palavras-chave: metafísica; ética; alteridade; educação.

RESUMEN: Este estudio realiza una aproximación entre Metafísica y Ética desde la perspectiva de Emmanuel Levinas. En un primer momento, revisa el sentido ontológico que el ser humano asume en el contexto de la razón occidental; a continuación, discute límites para la efectividad de una ética en el seno de la racionalidad instrumental capitalista. Estudiar el Ser no redunda necesariamente en entendimiento o acogida de lo que él manifiesta, aún más si los seres a los que nos referimos son humanos. Si la llamada condición posmoderna ha mostrado formas de ser en el mundo vaciadas de sentido y fundamentadas especialmente en la posibilidad de consumir, Levinas buscó profundizar el entendimiento de lo humano bajo el paradigma de la Alteridad. Otros autores referenciados en el texto concuerdan con la idea de que la cosmovisión antropocéntrica del mundo moderno se ha convertido en la raíz ideológica del capitalismo y de algunos de sus indeseables desdoblamientos, como guerras, males sociales y diversas formas de indiferencia. En cambio, al repensar el primado de la racionalidad occidental, podremos llegar a desarrollar una subjetividad acogedora. De este modo, partiendo de la perspectiva de Levinas, este texto pretende argumentar a favor de una ética que, además de humanizarnos, se constituya en una Metafísica de la Alteridad. Esta mirada ontológica redimensionada puede posibilitar nuevas comprensiones al campo de los Fundamentos de la Educación, así como propone la necesidad de construir nuevos modelos societarios.

Palabras clave: metafísica; ética; alteridad; educación.

\footnotetext{
* Doutora em Educação Ambiental (FURG), professora da rede pública do Magistério Estadual do Rio Grande do Sul, Técnica em Assuntos Educacionais no Instituto Federal de Educação, Ciência e Tecnologia do Rio Grande do Sul (IFRS) - Campus Rio Grande.
}

\footnotetext{
** Doutor em Educação; professor e pesquisador no Instituto de Educação e nos Programas de Pós-Graduação em Educação (PPGEDU/FURG) e Educação Ambiental (PPGEA/FURG) - Líder do Grupo de Pesquisa Fundamentos da Educação Ambiental e Popular (GFEAP/FURG). Editor-chefe da Revista Eletrônica do Mestrado em Educação Ambiental (REMEA).
}

NABAES, Thaís de Oliveira; PEREIRA, Vilmar Alves. A ética como metafísica da alteridade e suas possíveis contribuições aos fundamentos da educação. Revista Sul-Americana de Filosofia e Educação. Número 30: nov./2018-abr.2019, p. 109-120. DOI: https://doi.org/10.26512/resafe.vi30.28246 


\section{Introdução:}

O homem é um ser social. Ao postular isto, Aristóteles inaugurava uma discussão que se estendeu pela História da Filosofia e, mais do que teorizada, é colocada a todos nós como desafio diário. Como conviver com aquele que não sou $e u$, que me interpela a dar respostas e a não desviar o olhar? Estudar o Ser não redunda necessariamente em entendimento ou acolhida daquilo que ele manifesta, ainda mais se os seres a que nos referimos são humanos.

Neste sentido, a Metafísica nasceu como ramificação filosófica que pretendeu ser protephilosophia. Ao considerar o Homem com maior estatura ontológica que os demais entes, evidenciou-se o fato de que "é na procura que o homem se revela a si mesmo como homem, sendo essencialmente um animal metafísico" (SILVA, 1994, p.8).

É o homem, entre todos os entes, que se investe na busca de sentido para sua existência, que se lança no desafio de ir além da realidade empírica e que carrega em si o desejo de infinito. Entretanto, a partir especialmente da Era Moderna, o pensamento ocidental chegou a um nível de refinamento e objetivação em que (quase) tudo se tornou passível de verificação pelo cogito. Destarte, também o Ser do humano foi abarcado ou esquecido pela Razão que a tudo pretende explicar.

A nosso ver, a pretensão de implantar uma nova ordem no mundo sob o domínio da Razão mostrou-se um projeto fracassado. $\mathrm{O}$ aumento das desigualdades, as guerras e demais mazelas sociais, a depredação do ambiente natural e as diferentes formas de subjugação mantiveram a humanidade presa à condição de escravidão.
Segundo nossa compreensão, o sentido de Ser nas sociedades contemporâneas está permeado por uma Racionalidade notadamente reducionista, que ao colocar o homem fora da natureza, acabou instaurando a mais radical e generalizada alienação (MÜHL, 1996). Horkheimer e Adorno, na Dialética do Esclarecimento, fazem um diagnóstico da Racionalidade Ocidental a partir de uma questão fundamental: "Por que a humanidade, em vez de entrar em um estado verdadeiramente humano, está se afundando em uma nova espécie de barbárie”? (HORKHEIMER; ADORNO, 1985, p.11).

Desta forma, acrítica à Logo-logia feita por alguns pensadores contemporâneos demarca uma crise no pensamento metafísico. A cosmovisão antropocêntrica do mundo moderno se tornou a raiz ideológica do capitalismo e de alguns de seus indesejáveis desdobramentos. Em contrapartida, temos na proposta levinasiana um repensar do primado da Racionalidade Ocidental, com vistas ao desenvolvimento de uma subjetividade acolhedora. Ou seja, tal aporte teóricos e torna importante para discutirmos a possibilidade de uma vivência da alteridade em quaisquer que sejam nossos campos de relação, mesmo em sociedades tão marcadas por desigualdades e indiferenças como têm se mostrado a nossas.

\section{Horizontes Históricos da Metafísica}

O surgimento da Filosofia coincide com o deslocamento da cosmovisão mítica para uma procura por explicações racionais sobre a realidade. Impossível desconsiderar a contribuição dos gregos na formação do pensamento ocidental. Os pré-socráticos foram os primeiros a superar a justificação 
mítica, procurando nos elementos da natureza a explicação para os fenômenos do mundo sensível.

Este período na História da Filosofia foi marcado pela ideia de uma ordem natural regendo o Universo, não estando este mais dependente da veleidade dos deuses. O Universo estaria ordenado por princípios, passíveis de ser conhecidos pela Razão. O caos deu lugar ao cosmos e a Racionalidade humana foi colocada em busca da arché, ou fundamento constitutivo de toda a realidade.

Parmênides, por exemplo, situou o Ser na esfera na unicidade, baseado no princípio da não contradição: o Ser é /o Não-Ser não é. Embora o mundo se mostrasse múltiplo, para o eleata o Ser era imutável e imóvel, daí a impossibilidade de considerar o devir. Em contrapartida, Heráclito defende a ideia do pantha rei, ou "tudo flui". O conhecido aforismo do rio²tenta explicar o vir- a- ser ou como o Ser se transforma em algo que ainda não é. É a tese fundamental do devir e da mudança: ninguém se banha no mesmo rio duas vezes.

Já Sócrates desloca a questão do Ser para a esfera moral. Entendendo o homem como dotado de uma alma imortal, o Pai da Filosofia trabalha a ideia de essência a ser manifestada através do autoconhecimento. Sócrates acreditava na imortalidade da alma, daí que a história da educação se converta, nesta perspectiva, em uma história da educação da alma: sempre endereçada a um patamar superior, já que as paixões residiriam no corpo. $\mathrm{O}$ ateniense avaliava que mui-

\footnotetext{
${ }^{2}$ "Tu não podes descer duas vezes no mesmo rio, porque novas águas correm sempre sobre ti” (KUHNER, 2005, p.25).
}

tos homens se ocupavam em evoluir nas coisas externas, não no autoconhecimento. Para ele, a capacidade de perguntar desperta o mestre que há em cada indivíduo e, além disso, ajuda o homem a perceber a extensão da própria ignorância.

O ideário de Sócrates só nos foi dado a conhecer a partir de seus discípulos, em especial Platão. Na obra platônica, Sócrates encarna o paradigma do interlocutor filosófico (GIANNOTTI, 2011). Platão é considerado o primeiro grande metafísico, pois separa mundo sensível e mundo inteligível com a Teoria das Formas. Se o mundo físico é um mundo derivado, a Ideia é a suprema realidade ontológica, ou o Ser por excelência, o que dá início a uma série de dualismos na filosofia, como matéria/espírito, corpo/alma, essência/existência, etc.

Ainda no período clássico grego temos Aristóteles, que identifica o Ser com a substância (ousía).Ao submeter os princípios de seu mestre Platão a uma profunda revisão e crítica, Aristóteles sistematiza alguns dos principais temas filosóficos, colocando a questão do Ser como fundamental para o estabelecimento da Ciência (epistéme).

Se Platão tenta resolver o impasse dos pré-socráticos situando o Ser na esfera do inteligível, Aristóteles revaloriza a dimensão do sensível. O esforço da metafísica aristotélica é "tirar as ideias platônicas do lugar celeste e fundi-las dentro da mesma realidade sensível" (ROSSET \& FRANGIOTTI, 2012, p.59). A partir da Tábua das Categorias, da Doutrina do Ato e da Potência e da Doutrina das Quatro Causas, o Estagirita traça um novo caminho para a Metafísica, 
que se converte em uma teleologia imanente ${ }^{3}$.

Prosseguindo na história do pensamento filosófico, cabe relembrar que no final da Antiguidade e no período do Medievo, a questão do Ser foi identificada com premissas teológicas. Santo Agostinho e São Tomás de Aquino são dois grandes expoentes deste período, com a Teoria da Iluminação e Argumentação das Cinco Vias, respectivamente. A Teoria da Iluminação de Santo Agostinho difere da doutrina platônica da reminiscência justamente pelo papel que exerce a "Luz Eterna da Razão", que procede de Deus. Em A Cidade de Deus, Santo Agostinho antecipa em doze séculos o cogito cartesiano a respeito da certeza da existência baseada na atividade da Razão.

O Homem 4 , na perspectiva destes dois filósofos, identifica-se com sua alma, tendo a missão de reconduzir-se ao $\mathrm{Uno}^{5}$, através da conversão ou tendência para o Alto. Esta escatologia, um dos fundamentos da fé cristã, aponta para uma nova forma de pensar a História, agora vista como História da Redenção.

Com a decadência dos paradigmas do mundo medieval, o Ser deixa de ser tratado como abstração. Se na Idade Média o homem era sinônimo de sua alma, na Modernidade este Ser/Homem torna-se sinônimo de sujeito, aquele capaz de dar sentido à realidade. Esta cosmovisão antropocêntrica inaugura um período de crise no

3Tendência dos seres caminharem em direção à realização de suas potencialidades.

4 Vocábulo que neste texto tem o sentido de Humanidade. 5 Os filósofos do medievo foram influenciados por Plotino (205 d.C-270 d.C), que formulou a chamada Metafísica do Uno. Embora não tenha identificado o Uno com um Deus pessoal, Plotino descreveu seus atributos, que serviram de inspiração para a formulação da doutrina cristã. pensamento metafísico, onde, especialmente a partir de Kant, dá-se a passagem de uma teoria do ente (ontologia) a uma teoria do conhecimento (epistemologia).

No século XV, época de transição entre as Idades Média e Moderna, inicia um período de questionamento e efervescência intelectual, onde ocorrem várias mudanças de cunho artístico, religioso, político, comercial e científico. Neste contexto, Descartes elabora um método para conhecer a verdade, desconstruindo a ideia teocêntrica predominante no período anterior.

Segundo a concepção cartesiana, embora os sentidos possam enganar, a Ciência, pelo uso rigoroso da Razão, chegaria ao verdadeiro conhecimento. O filósofo considera como verdade indubitável a existência do sujeito pensante. Se o sujeito pensa é porque ele existe, eis o famoso cogito cartesiano: "penso, logo existo". Ao submeter as opiniões prévias ao mais radical ceticismo, Descartes estabelece um preceito metodológico básico: aceitar como verdadeiro apenas aquilo que for evidente ou examinado a partir de exigências rigorosamente racionais.

A partir dos séculos XVIII e XIX a concepção de Ser esteve relacionada com aspectos de propriedade como em Locke e Rousseau, por exemplo. Rousseau considera que o ser humano nasce inteiramente bom e tem seu comportamento corrompido pela sociedade, que representa a origem da opressão e da desigualdade. Atribui ao desenvolvimento da Razão o fim da ligação idílica entre o homem e a natureza, destacando que o estado de natureza é uma síntese romântica da vida comunitária, onde a ignorância não permite a guerra, pois não 
há propriedade privada e egoísmo. Os homens em estado de natureza seriam bons, livres e felizes.

No século $\mathrm{XX}$, temos os aportes da Teoria Crítica problematizando sobretudo a Racionalidade Instrumental, que se coloca como nova forma de Ser-no-mundo. A partir desta ótica, percebe-se a existência de outro tipo de construção ontológica, que vem se mostrando predominante na sociedade capitalista: o Ter como base para estruturação do Ser e para os contratos sociais.

Autores como Emmanuel Levinas (1906-1995) e Enrique Dussel (1934) aprofundaram o entendimento do humano sob o paradigma da alteridade. A chamada condição pós-moderna tem mostrado formas de Ser esvaziadas de sentido e fundamentadas especialmente na possibilidade de consumir. Neste texto, após termos apresentado brevemente os horizontes históricos da Metafísica, assumindo grandes omissões, apresentamos outras perspectivas de compreensão destes fenômenos, dando seguimento à discussão do que tem significado Ser nas sociedades ocidentais hodiernas.

\section{A Ética como Metafísica da Alteridade}

A proposta de Emmanuel Levinas se inscreve na perspectiva de romper com o individualismo e a indiferença, desenvolvendo um sentido de responsabilidade pelo Outro, que é aquele que está para além do $E u$. O filósofo parte da ideia de que o pensamento ocidental se constituiu em totalidade ao tentar neutralizar as diferenças, abarcando com o discurso toda a possibilidade de manifestação da existência.
Ao fazer uma avaliação do legado da Ontologia e seu conjunto de categorias, Levinas apontou que a existência do Outro é a base da Ética, uma responsabilidade que não se pode escolher ou recusar. A Ética, ao se constituir num imperativo básico de convivência, faz com que passemos de animais a humanos. Nesse sentido, ela é tomada como Metafísica da Alteridade: é a possibilidade de transcendência da Totalidade Impessoal do Ser em direção a Alteridade do Outro.

Francês nascido numa família judaica da Lituânia, Levinas sofreu a violência nazista da II Guerra. As mortes e o terror provocados pelo Holocausto imprimiram no filósofo experiências que o levaram a repensar as bases da Racionalidade Ocidental, que foi convertida em justificativa para dominação. $\mathrm{O}$ entendimento de que a responsabilidade para com o Outro antecederia a consciência reflexiva, faz com que o verdadeiro encontro com este Outro não permita uma atitude de indiferença, pois é no facea-face humano que está o essencial da ética: "sua intenção transcendente" (LEVINAS, 1980, p.16).

As categorias Ser (Antiguidade e Idade Média) e Eu (a partir da Era Moderna)encontram-se nesta perspectiva totalizante, pois impelem à massificação. Tudo que não se insere dentro da Totalidade é definido como Não-Ser, bárbaro ou mesmo mitológico. A filosofia levinasiana aponta outras concepções ao propor o exercício da alteridade radical, como Outro, Mesmo, Rosto, Infinito e Desejo Metafísico, por exemplo.

Extrapola o objetivo deste texto aprofundar cada uma destas acepções, po- 
rém é necessário que falemos brevemente sobre elas, a fim de situarmo-nos no pensamento do autor. Para Levinas, a Mesmidade se refere ao Eu em si: "O Eu é o Mesmo perante a Alteridade" (LEVINAS, 1980, p.24). A subjetividade deveria estar situada no plano ético e não encerrada em amarras, que levam a um contexto de nadificação (DALLA ROSA, 2011).

O Outro Metafísico é a alteridade não formal, aquilo que está fora do Mesmo. O Outro é sempre exterioridade em relação ao Eu, é mistério inesgotável e aquele que suscita o agir moral. Os grandes problemas do século XX como as guerras, regimes ditatoriais e todas as formas de violência foram direta ou indiretamente criados por uma cultura ególatra, que, entre outras coisas, suspendeu a moral.

A tendência do Mesmo é tomar o Outro para si, anulando-o. A Alteridade é a possibilidade de o Outro e o Mesmo estarem mais próximos, o momento em que o Mesmo se deixa interpelar. Levinas faz uma crítica radical ao primado da Ontologia, que se mostra insuficiente para exprimir a realidade do humano. Para Levinas:

O primado do Mesmo foi a lição de Sócrates: nada receber de Outrem a não ser o que já está em mim, como se, desde toda eternidade, eu já possuísse o que me vem de fora. Nada receber ou ser livre. A liberdade não se assemelha à caprichosa espontaneidade do livre arbítrio. O seu sentido último tem a ver com a permanência do Mesmo, que é a Razão (LEVINAS, 1980, p.31).

Por fim, o Rosto é o que está para além da face, da caracterização do corpo, da origem, de tudo aquilo que informa quem somos de uma forma material: "O modo como o Outro se apresenta, ultrapassando a ideia do Outro em mim, chamo-o, de fato, Rosto" (LEVINAS, 1980, p.37). Segundo Levinas, diante do Outro, o sujeito se descobre responsável e lhe vêm à ideia o Infinito. Esta Ideia de Infinito tem origem especialmente no desenho formal da Terceira Meditação de Descartes.

$\mathrm{Na}$ Terceira Meditação, Descartes tenta demonstrar racionalmente a existência de Deus. Entende a ideia de Infinito como não provinda do cogito, porque o homem sendo finito e imperfeito não poderia pensar em algo infinito e perfeito. O Infinito para Descartes é plena exterioridade em relação ao cogito e transborda toda possibilidade de conceituação ou representação derivada. Em Descartes, essa ideia exterior se apresenta como Deus, enquanto que em Levinas ela é o Rosto.

Esta construção filosófica é a inspiração para pensar a relação entre o Mesmo e o Outro. O Outro é total exterioridade, não pode ser englobado por conceitos, supera qualquer ideia que se possa ter a partir da contemplação de seu Rosto. O filósofo vê nesse elemento a possibilidade de romper com o "império" do Mesmo, sendo simultaneamente um questionamento à soberania do Eu. Esta Ideia de Infinito é também pura inadequação do pensamento que a pensa:

A ideia do infinito não é uma noção que uma subjetividade forje casualmente para refletir uma entidade que não encontre fora de si nada que a limite, que ultrapassa todo o limite e, por isso, infinita.[...] A ideia do infinito é o modo de ser - a infinição do infinito.[...] A sua infi- 
nição produz-se como revelação, como uma colocação em mim da sua ideia. Produz-se no fato inverossímil em que um ser separado fixado na sua identidade, o Mesmo, o Eu contém, no entanto, em si - o que não pode nem conter, nem receber apenas por força da sua identidade. A subjetividade realiza essas exigências impossíveis: o fato surpreendente de conter mais do que é possível conter (LEVINAS, 1980, p.14).

Ao não mais pensar o Outro a partir da subjetividade do Eu, Levinas vislumbra a subjetividade em outra perspectiva: como acolhida e hospitalidade. A abertura em relação ao Outro suscita o Desejo Metafísico, que não é aquele que procura a satisfação pela posse, mas é um desejo desinteressado. A cultura ocidental inclui-se num contexto em que há luta entre poderes, que buscam reduzir a identidade do Outro à identidade do Eu. O desejo em nossa cultura é invariavelmente vontade de assimilação e posse. A proposta levinasiana busca o núcleo mais profundo do ser humano: ser para, sem mediações (NODARI, 2002). Em Totalidade e Infinito, Levinas afirma que:

Para além da fome que satisfaz, da sede que se mata e dos sentidos que se apaziguam, a metafísica deseja o Outro para além das satisfações. (...) Desejo sem satisfação que, precisamente, entende o afastamento, a alteridade e a exterioridade do Outro (LEVINAS, 1980, p.22).

Ao estabelecer um novo ponto de partida para ética (não um sistema de normas racionais, mas a ruptura com a ordem Identidade-Ser-Totalidade), o filósofo dá novo sentido também à transcendência, compreendendo-a como movimento de Alteridade, em que o Eu se torna, pela injunção ao Rosto, responsável e bom (PIVATTO, 1992). A Alteridade é condição para o rompimento com o individualismo e a indiferença, e imprescindível para nossa evolução moral. Destarte, em Levinas, mais que desejo de sabedoria teórica, a filosofia é sabedoria do amor.

\section{Há possibilidade da vivência da Alte- ridade no contexto capitalista?}

As características do modo de produção capitalista geram uma crise que se manifesta não apenas economicamente. $\mathrm{O}$ capitalismo necessita da relação de opressão para subsistir. Há a evocação de uma liberdade que não se concretiza plenamente, pois a promessa de progresso material, por exemplo, não tem como se efetivar para todos, pois o sistema não se sustentaria.

No contexto das sociedades capitalistas, o objeto da consciência humana acaba por se restringir ao acúmulo de capital e ao que seus subprodutos representam: poder, opressão, status; mais poder, mais opressão, maisstatus, estabelecendo um círculo vicioso em torno do dinheiro, que é um símbolo concreto das perversidades do sistema. Nas palavras de Marx,

(...)cada homem especula sobre a maneira como criar no outro uma nova necessidade para o forçar a novo sacrifício, o colocar em nova dependência, para o atrair a uma nova espécie de prazer e, dessa forma, à destruição. [...] Todo produto novo constitui uma nova potencialidade de mútuo engano e roubo. $\mathrm{O}$ 
homem torna-se cada vez mais pobre como homem, necessita cada vez mais de dinheiro, para poder tomar posse do ser hostil. [...] A necessidade de dinheiro constitui, assim, a verdadeira necessidade criada pelo moderno sistema econômico e é a única necessidade que ele produz. [...] $O$ excesso e a nãomoderação tornam-se a sua verdadeira medida. É o que se manifesta no plano subjetivo, em parte porque a expansão dos produtos e das necessidades se transforma em subserviência engenhosa e sempre baseada nos apetites inumanos, corrompidos, antinaturais e fantasiosos. (MARX, 2006, p.149).

A produção teórica de Marx - além de ser uma crítica radical ao modo de produção capitalista - elucida como se dão as relações de exploração humana em uma sociedade que subsiste a partir da desigualdade. Um de seus pressupostos é a afirmação de que as condições materiais de existência são a base da estrutura social e da consciência humana. Sendo o trabalho situação histórica e permanente de autoprodução do gênero humano (LOPEZ-VELASCO, 2008, p. 37), a exploração da força de trabalho com vistas à acumulação de capital leva à alienação em diferentes níveis.

Nesta perspectiva, é possível afirmar que a fase econômico-social que por ora nos encontramos difere das anteriores no sentido em que os avanços dos meios tecnológicos (especialmente pela quantidade de instrumentos e velocidade de transmissão de dados) contribuem para a coesão das massas. Já não somos controlados apenas pelo tic-tac do relógio da fábrica, mas atingidos em praticamente todas as esferas de nossa vida pública: no lazer, nas religiões, nas artes, etc. Também estes espaços ajudam a criar incessantes necessidades, que estimulam o individualismo e resultam em uma nova espécie de escravidão. É o império do Mesmo, conforme Levinas. Imersos na Totalidade, não temos olhos para o Outro, o que inviabiliza a vivência plena da Alteridade. É como se nossas necessidades fossem as mais urgentes ou as únicas possíveis de ser atendidas. E para isto fazemos tudo ou quase tudo. Basta fechar os olhos para ser indiferente.

Os desvios da Razão se mostraram concretamente nas grandes barbáries do século XX (regimes totalitários, guerras, genocídios), onde a dissolução do indivíduo na coletividade levou à supervalorização do que Matos (2005) chama de universais abstratos: Povo, Nação, Pátria, etc. Conforme esta interpretação, os universais acabam por se tornar "constructos da identidade a encobrir as divisões e conflitos neles existentes” (MATOS, 2005, p.46), ou seja, é mais um artifício para subsumir o humano numa generalidade conceitual.

Na medida em que a própria Razão tem se tornado responsável pela produção do Irracional criou-se um novo mito, que consiste na "crença moderna na onipotência da ciência e da técnica" (DELACAMPAGNE, 1997, p. 176). Não estamos libertos do medo e de nossas angústias, pelo contrário: criamos novos mitos. Estes já não explicam o desconhecido tal como outrora, mas conduzem à impossibilidade da reflexão como transcendência (GUR-ZE'EV, 2006).

As posições de Levinas são radicais e de certo modo incômodas, se pensarmos nas diferentes maneiras em que fomenta- 
mos o distanciamento do Outro e também em como alimentamos - voluntária ou involuntariamente - o sistema do capital. A Alteridade radical exige que o Outro sempre nos anteceda, em um contexto em que o apelo à justiça e à responsabilidade para com este Outro nunca é plenamente atendido.

Dificilmente somos capazes de enfrentar a violência sem gerar mais violência, ou de abrirmos mão do ímpeto de satisfazer nossas próprias necessidades em primeiro lugar. Mesmo quando nos sentimos atendidos naquilo que consideramos básico ${ }^{6}$, nem sempre a realidade dos que nada têm nos afeta a ponto de agirmos altruisticamente.

O que nos move e comove? Levinas escreveu em um contexto pós-guerra, tendo vivido experiências dolorosas de opressão e mesmo assim é notável que não assuma um discurso de vitimização. Ele acredita no encontro humano como fundador de uma nova ética. Esta ética prescinde da legalidade para regular as relações, porque está fundada no deslocamento de si. A reconstrução da subjetividade humana não se daria mais partindo do estereótipo do "sujeito autônomo e livre", mas a partir da Ideia de Infinito: a abertura ética e desinteressada ao que o Outro traz.

Muitos discursos sobre igualdade social parecem incitar que a superação da relação opressor-oprimido se dê com a inversão dos polos. Trocar as posições sociais não trará a ruptura com a velha ordem, talvez apenas satisfaça momentaneamente um desejo de retaliação dos males sofridos. A

${ }^{6}$ Não apenas alimento e abrigo, mas também nas necessidades criadas pelo capital. experiência moral - a Alteridade Radical vê no futuro a consumação da Ideia do Infinito.

Perguntar se há possibilidade da vivência da alteridade no contexto capitalista é uma questão de resposta já prevista. Levinas postularia exigências que são totalmente contrárias aos objetivos da Sociedade do Capital. Entretanto, nossa resposta enquanto educadores, impregnados do sentido ético que o autor nos infunde, poderia ser um compromisso e ato de esperança em transformar o que há tanto já está posto.

\section{Considerações finais:}

O estudo aqui apresentado preocupou-se em apontar, a partir do pensamento de Levinas, a necessidade de repensarmos as ontologias clássicas. A proposição de uma nova Ética, cujo componente central embasa o reconhecimento de uma Metafísica da Alteridade, está profundamente relacionada ao deslocamento do Eu, à abertura ao Outro e aos saberes não reconhecidos.

Em nosso entendimento, esses pressupostos contribuem de modo decisivo para revigorar os Fundamentos da Educação, possibilitando em nossas práticas educativas a construção de uma nova ética, que traz as seguintes reivindicações:

- a necessidade de rompermos com o individualismo, a indiferença e a competitividade ainda tão presentes em espaços educativos;

- a exigência ética de transcendência da Totalidade Impessoal do Ser em direção a Alteridade do Outro; 
- a superação dos limites da ontologia tradicional, que, a partir de uma argumentação totalizante, classifica tudo o que nela não se insere como NãoSer, inaceitável, indigno de reconhecimento e escuta;

- a necessidade de redefinição do espaço humano no Cosmo, com a melhor relação entre seres vivos e não-vivos;

- a ampliação da percepção e vivência da realidade, superando uma visão de mundo antropocena, em favor de uma perspectiva cosmocena (PEREIRA, 2016);

- o reconhecimento da aprendizagem como processo de valorização da vida.

Tantas outras exigências podem ainda ser citadas, daí a relevância de compreendermos que a Alteridade é condição para o rompimento com o individualismo e a indiferença, portanto imprescindível para nossa evolução moral e para outros endereçamentos educativos. As diferentes crises que ora experimentamos (ambientais, religiosas, políticas, axiológicas, etc.) nos indicam uma crise ainda maior, que é a escassez de sentido vivencial.

Em tempos de subjetividades massificadas, moldadas a partir de princípios de identidade que forjam a ilusão de existência do individual, reforçamos a lógica que dá primazia à capacidade funcional dos sujeitos, minimizando as demais dimensões humanas, ou até mesmo negando-as.
Em nosso entendimento, ao buscarmos compreender estes fenômenos, nos endereçamosà reconstrução de nossas relações sobre o legado de outra Racionalidade, que subverta o logocentrismo das Ciências Modernas e seja capaz de abrir novas perspectivas para a promoção da vida. Se nas sociedades capitalistas nos deparamos com um crescente processo de racionalização orientado para a maximização dos lucros, do consumo, da eficiência e da produtividade, a partir dos princípios de uma Metafísica da Alteridade temos outro paradigma: o de uma subjetividade acolhedora.

Na modernidade, fomos convocados não apenas a nos distinguir dos outros seres da natureza, mas a efetivamente separarmonos. Talvez isto explique a destruição em larga escala do que consideramos estar fora de nós (o Outro, de Levinas), o que inclui a subjugação de outros povos como traço da dominação do homem-pelo-homem.

É incoerente e inócuo almejar uma revolução ideológica e valorativa sem uma mudança nos paradigmas que orientam a educação. As discussões pedagógicas precisam voltar-se para a valorização dos saberes que partem de identidades plurais, observando o mundo como potencialidade de vida, desconstruindo os referenciais que incitam os indivíduos ao mero ganho econômico, ou à relação com os pares como fator de exclusão social.

A superação da relação sujeito-objeto também precisa ser estendida aos espaços educativos, favorecendo a cultura da colaboração, do cuidado e do respeito mútuo. Voltar o olhar ao entorno, às diferentes culturas e à história dos sujeitos não significa desprezar a construção das ciências mais 
tradicionais (inclusive das ciências e teorias da educação), mas ampliar as formas de conhecer e apreender o mundo, que, desde antes de qualquer intenção de educação formal, já vem constituindo o Ser de cada um.

Ao compreender o Ser no saber, criase outra relação pedagógica, negando as certezas insustentáveis, as categorias conceituais inflexíveis que não têm estimulado mentalidades para gerar o inédito. A educação não pode se sujeitar a ser treinamento para, porque deve dar lugar também ao não-saber, que é infinitamente maior do que efetivamente conhecemos. Neste senti- do, as relações pedagógicas devem fugir do modelo de competitividade, dando lugar às potências do Ser.

Se entendermos que a Educação é um processo de construção social, faz todo sentido buscara desconstrução do saber onicompreensivo e totalizante, integrando o conhecimento sensível e o racional, valorizando os saberes e restaurando a relação entre Ser, vida e conhecimento. Isso pode ser possível a partir do deslocamento compreensivo ontológico em que a subjetividade deveria estar situada no plano ético e não encerrada em amarras, que levam a um contexto de nadificação.

\section{Referências}

DALLA ROSA, Luís Carlos. A alteridade e a relação pedagógica no pensamento de Enrique Dussel. In: Revista Diálogo. Canoas, n1ㅗ, p. 131-144, jul-dez 2011. Disponível em: http://www.revistas.unilasalle.edu.br/index.php/Dialogo/article/view/186/200 <Acessado em: 9 de setembro de $2016>$

DELACAMPAGNE, Christian. História da Filosofia no Século XX. Rio de Janeiro: Jorge Zahar, 1997.

GIANNOTTI, José Arthur. Lições de Filosofia Primeira. São Paulo: Companhia das Letras, 2011.

GUR-ZE’EV, Ilan A Bildung e a Teoria Crítica na Era da Educação Pós-Moderna. Revista Linhas Críticas. p. 5-21. Disponível em:

http://periodicos.unb.br/index.php/linhascriticas/article/viewArticle/1673< Acessado em: o9 de setembro de $2016>$

HORKHEIMER, Max; ADORNO, Theodor. Dialética do Esclarecimento: Fragmentos Filosóficos. Rio de Janeiro: Jorge Zahar, 1985.

KUHNER, Remberto Francisco. Os Pré-Socráticos. São Paulo: Nova Cultural, 2005.

LEVINAS, Emmanuel. Totalidade e Infinito. Lisboa: Edições 70, 2000.

LOPEZ VELASCO, Sírio. Introdução à Educação Ambiental Ecomunitarista. Rio Grande: Editora da FURG, 2008.

MARX, Karl. Manuscritos Econômico- Filosóficos. São Paulo: Martin Claret, 2006. 
MATOS, Olgária. A Escola de Frankfurt - Luzes \& Sombras do Iluminismo. São Paulo: Moderna, 2005.

MÜHL, Eldon Henrique. Crítica à Racionalidade Instrumental: As contribuições de Adorno e Horkheimer. In; CENCI, Angelo (org.) Ética, Racionalidade e Modernidade. Passo Fundo: EdiUPF, 1996.

NODARI, Paulo Cesar. O Rosto como apelo à responsabilidade e à justiça em Levinas.In: Síntese - Revista de Filosofia. Belo Horizonte. v.29, no 94, 2002. p. 191-220. Disponível em: http://www.faje.edu.br/periodicos/index.php/Sintese/article/viewArticle/527< Acessado em: 07 de setembro de $2016>$

PEREIRA, Vilmar Alves. Ecologia Cosmocena: a redefinição do espaço humano no cosmos. $1^{\mathrm{a}}$ ed. Juiz de Fora: Garcia Edizioni, 2016.

PIVATTO, Pergentino S. A ética de Levinas e o sentido humano: crítica à ética ocidental e seus pressupostos. In: Veritas. Porto Alegre, v.37, n.147, set. 1992.

ROSSET, Luciano \& FRANGIOTTI, Roque. Metafísica antiga e medieval. São Paulo: Paulus, 2012.

SILVA. Márcio Boldada. Metafísica e Assombro - Curso de Ontologia. São Paulo: Paulus, 1994.

Recebido em: 03/08/2017

Aprovado em: 31/10/2019 